\title{
The Relationship Between Fasting During The Ramadan Month and Acute Renal Colic Admissions Rate to The Emergency Department
}

\author{
Kamil Malshy*, Omri Nativ, Shadi Badaan, Yaron Ofer, Azik Hoffman, Ariel Zisman, Gilad E. Amiel \\ and Michael Mullerad
}

Department of urology, Rambam Health Care Camapus, Israel

*Corresponding author: Kamil Malshy, Department of urology, Rambam Health Campus, 8th HaAliya HaShniya st, Haifa, Israel.

To Cite This Article: Kamil Malshy. The Relationship Between Fasting During The Ramadan Month and Acute Renal Colic Admissions Rate to The Emergency Department. 2020 - 9(3). AJBSR.MS.ID.001393. DOI: 10.34297/AJBSR.2020.09.001393.

Received: 眥 : May 20, 2020; Published: 海 June 30, 2020

\begin{abstract}
Objectives: Dehydration is a risk factor for the development of urinary stones. Ramadan fasting restricts from consuming food and fluids for over 15 hours a day for 28 consecutive days. Our study aim was to assess whether fasting during Ramadan increases the number of Renal Colic (RC) Emergency Department (ED) visits.
\end{abstract}

Methods: We reviewed the medical records of patients who applied to the ED with RC during the Ramadan period between years 2016 to 2018. We divided the population into Muslim and non-Muslim patients and compared them with patients who applied to the ED two weeks before and after the Ramadan period (control).

Results: The study included 399 patients who referred to the ED due to renal colic. 109 of them were Muslims and 290 non-Muslims. During the Ramadan period, 70 Muslims (33.1\%) and 141 non-Muslims (66.9\%) visited ED, compared to 39 (20.7\%) Muslims and 149 (79.3\%) non-Muslims during the control period. There was an increase of approximately 79\% in Muslim ED visits during the month of Ramadan compared to the control period ( $p$-value $=0.0068$ ). This trend was observed in each of the study years, and in men and women separately.

Conclusion: Fasting during the month of Ramadan causes a statistically significant increase in the rate of visits to the ED due to renal colic. Muslim patients are at increased risk of developing clinically significant stone disease. Those with known stone disease should be informed about the increased risk for renal colic during fasting.

Keywords: Ramadan, Renal colic, Nephrolithiasis, Risk Factors, Emergency Department, Muslim and non-Muslim, Ureteroscopy, Adrenocorticotropic hormone, Antidiuretic Hormone, Supersaturation, Crystallization

Abbreviations: RC: Renal Colic; ESWL: Extracorporeal Shockwave Lithotripsy; PCNL: Percutaneous Nephrolithiasis; NCCT: Non-Contract Computed Tomography; ED: Emergency Department; URS: Ureteroscopy; ADH: Antidiuretic Hormone; ACTH: Adrenocorticotropic hormone

\section{Introduction}

Urinary stone disease is a common pathological condition affecting approximately $7-10 \%$ of the population [1]. About one third of those diagnosed with nephrolithiasis will have a recurrent symptomatic stone event within 10 years if no preventive measures will be taken [2]. One of the main leading etiologies of urolithiasis is inadequate hydration where low urine volumes increase the solutes concentration and promote urinary stasis, which allows supersaturation, crystallization and stone formation [3]. An acute renal colic event represents obstruction of the urinary tract which is manifested by severe flank pain and tenderness. Once diagnosed the initial management of an obstructing urinary stone is done by pain management, medical expulsive therapy and adequate hydration. If necessary, drainage of the obstructive renal unit can be performed $[4,5]$. There are several definitive treatments for urinary stone disease including: stone extraction by either laser fragmentation or stone removal by ureteroscopy, ESWL (Extracorporeal Shockwave Lithotripsy) and PCNL (Percutaneous Nephrolithiasis) [6].

Many epidemiological studies have well established the causative relationship between stone formation and dehydration and suggested that patients with a history of urinary stone disease should increase the fluid intake in order to prevent stone formation [7]. These preventive measures are not carried out by Muslims 
who are fasting during the Ramadan month. During this period, religious Muslims are obligated to abstain from eating and drinking from dawn to dusk (during 12-18 hours) for 28 consecutive days $[8,9]$. The aim of our study was to assess whether fasting during the Ramadan month increases the incidence and severity of renal colic admissions to the Emergency Department (ED).

\section{Methods}

\section{Study Design}

This is a retrospective case control study carried out by the Emergency and Urology departments at Rambam Health Care Campus, Haifa, Israel between May 2016 to Jan 2019. Our hospital is the only tertiary hospital in the north of Israel and is considered a high-volume urolithiasis referral center. Following approval by the Institutional Research Board (IRB) (RMB-0254-16), data was gathered from computerized medical files using specific ICD-9 discharge codes: Calculus of ureter and Renal Colic.

\section{Inclusion criteria}

A. Acute renal colic event as indicated by the ICD-9 relevant code.

B. Proven ureteral calculus according to Computed Tomography (CT) scan.

C. Age: $\geq 18$.

\section{Exclusion criteria}

A. Known metabolic stone disease.

B. Stone removal procedure (URS, ESWL, PCNL) $<3$ months prior to admission.

C. Second admission to the ED during the Ramadan month because of a renal colic event.

We reviewed the medical records of 1034 renal colic events that occurred during the Ramadan month in 3 consecutive years (2016-2018). Out of all these cases, 399 patients met the inclusion criteria. The study examined two populations:

1. Muslim patients who admitted to the ED with an acute renal colic event during the Ramadan month in these years.

2. The control population was composed of two subgroups:

a. Muslim patients who admitted to the ED with an acute renal colic event during the two weeks before or after the Ramadan month in these years.

b. Non-Muslim patients who admitted to the ED during the study period.

\section{Primary End Point}

The incidence of renal colic event with an obstructing ureteral stone during the Ramadan month.

\section{Secondary End Point}

The severity of the renal colic event among the two groups. Severity was measured according to one of the following: renal function deterioration, admission to the urology department and the need for an emergent intervention.

\section{Statistical Analysis}

Fisher's Exact test for discrete variables and Mann-Whitney test for ordinal and continuous variables were used for statistical analysis. $\mathrm{p}<0.05$ was considered statistically significant. All statistical analyses were performed using SPSS software (SPSS 25.0; SPSS Inc. Chicago, IL, USA).

\section{Results}

\section{ED Visits and Demographics}

As described in Table 1, during the study period, 399 patients were admitted to the ED because of ureteral calculus. Of which 109 (27\%) were Muslims (85 male and 24 female). The remaining 290 (73\%) were non-Muslims (238 male and 52 female). With respect to the Muslim patients, we observed significantly higher rate of admission to the ED due to renal colic during the Ramadan month vs Not-ramadan control period (70 (31.6\%) patients vs 39 (20.7\%) patients respectively,p=0.0068). It should be mentioned that during the Ramadan period slightly more female patients were admitted to the ED (24.3\% VS 18\%).

Table 1: Patient demographic during the Ramadan and non-Ramadan periods.

\begin{tabular}{|c|c|c|c|c|c|}
\hline \multirow[b]{2}{*}{$\begin{array}{c}\text { Total Number } \\
(\mathrm{N}=399)\end{array}$} & \multicolumn{2}{|c|}{ Ramadan } & \multicolumn{2}{|c|}{ Non-Ramadan } & \multirow{2}{*}{$\begin{array}{c}\text { p-Value } \\
0.1193\end{array}$} \\
\hline & 211 & $55.3 \%$ & 188 & $44.7 \%$ & \\
\hline Muslims (N=109) & 70 & $31.6 \%$ & 39 & $20.7 \%$ & 0.0068 \\
\hline $\begin{array}{l}\text { Non-Muslims } \\
\quad(\mathrm{N}=290)\end{array}$ & 141 & $68.4 \%$ & 149 & $79.3 \%$ & 0.561 \\
\hline \multicolumn{6}{|c|}{ Muslim Population } \\
\hline & \multicolumn{2}{|c|}{ Ramadan } & \multicolumn{2}{|c|}{ Non-Ramadan } & p-Value \\
\hline Age (Mean) & \multicolumn{2}{|c|}{46.5} & \multicolumn{2}{|c|}{46.15} & 1 \\
\hline Men & 53 & $62.3 \%$ & 32 & $37.6 \%$ & 0.075 \\
\hline Women & 17 & $70.8 \%$ & 7 & $29.2 \%$ & 0.013 \\
\hline
\end{tabular}




\begin{tabular}{|l|l|l|l|l|l|}
\hline 2016 & 19 & $61.3 \%$ & 11 & $36.7 \%$ & 0.2 \\
\hline 2017 & 19 & $61.2 \%$ & 12 & $38.7 \%$ & 0.1 \\
\hline 2018 & 32 & $66.7 \%$ & 16 & $33.3 \%$ & 0.11 \\
\hline \multicolumn{2}{|r|}{$\quad \mathrm{P}<0.05:$ Muslims in Ramadan VS Muslims in Non-Ramadan period } \\
\hline
\end{tabular}

\section{Severity of Events}

When the severity of the stone event was considered we observed no differences in the studies parameters between patients admitted during the Ramadan or the non-Ramadan periods. This was manifested by similar stone diameters (4.83 $\mathrm{mm}$ compared with $5.09 \mathrm{~mm}$ respectively), decreased renal function $(21.4 \%$ vs $20.5 \%$ respectively), need for hospitalization $(38.5 \%$ and $38.4 \%$ respectively) or need for intervention among those who were admitted to the hospital (59.3\% vs $53.3 \%$ respectively) (Table 2 ).
In order to verify the causative relationship between the Ramadan period and the occurrence of stone events a separate analysis of non-Muslim patients who were not subjected to dehydration was also studied. No differences were noted in the admission rate to the ED due to acute renal colic event during the studied periods $(48.6 \%$ during the Ramadan vs $51.4 \%$ in the non-Ramadan periods), this is significantly different from the Muslim population whose rate of admission to the ED during the Ramadan period was 1.79, higher than their rate of admission at the non-Ramadan period (Figure 1).

Table 2: Severity of renal colic events among the Muslim population during the Ramadan and non-Ramadan periods.

\begin{tabular}{|c|c|c|c|c|c|}
\hline \multirow[b]{2}{*}{ Acute Kidney Injury } & \multicolumn{2}{|c|}{ Ramadan } & \multicolumn{2}{|c|}{ Non-Ramadan } & \multirow{2}{*}{$\begin{array}{c}\text { p.value } \\
0.59\end{array}$} \\
\hline & $15 / 70$ & $21.4 \%$ & $8 / 39$ & $20.5 \%$ & \\
\hline Admission After First Visit & $27 / 70$ & $38.5 \%$ & $15 / 39$ & $38.4 \%$ & 1 \\
\hline Operation after first admission (if admitted) & $16 / 27$ & $59.2 \%$ & $8 / 15$ & $53.3 \%$ & 0.112 \\
\hline Stone Size (Mean cm) & \multicolumn{2}{|c|}{4.83} & \multicolumn{2}{|c|}{5.09} & 1 \\
\hline \multicolumn{6}{|c|}{$\mathrm{P}<0.05$ : Muslims in Ramadan VS Muslims in Non-Ramadan period } \\
\hline
\end{tabular}

Total population ED visits

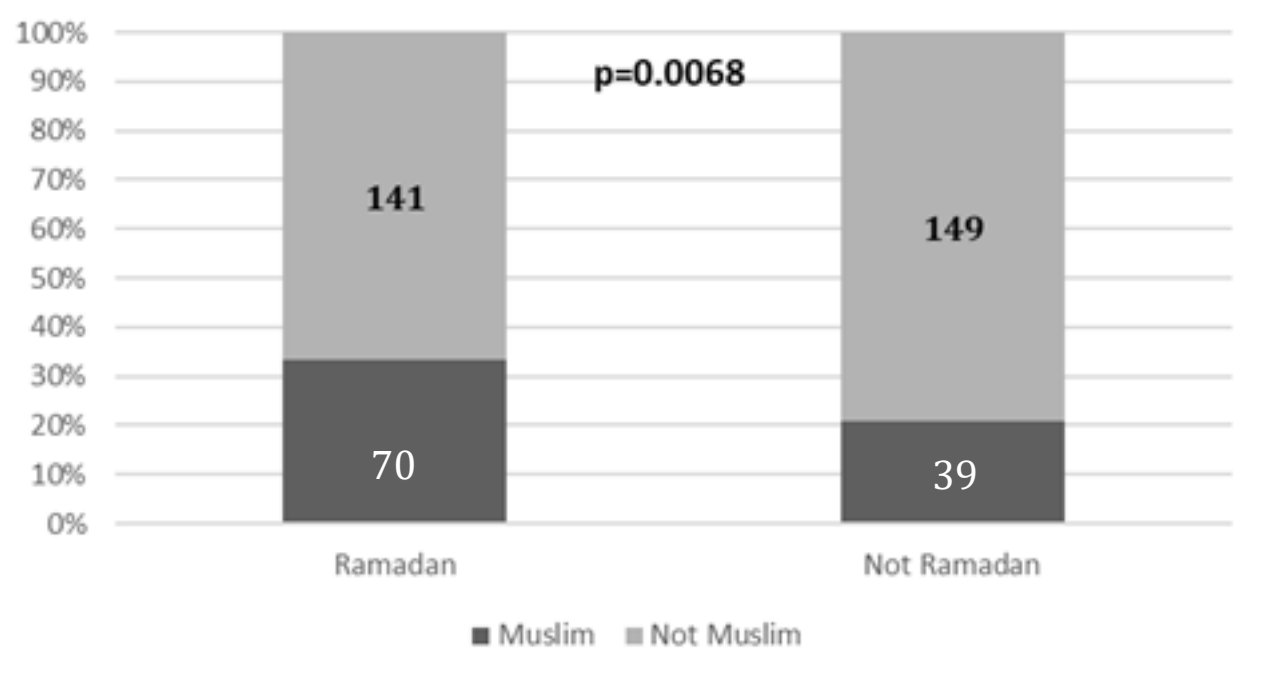

Figure 1: Number of renal colic ED admissions among the Muslim population during Ramadan and non-Ramadan periods. $\mathrm{P}<0.05$ : Muslims in Ramadan VS Muslims in Non-Ramadan period

Timing of Renal Colic and the Breaking of the fast "iftar"

When examining the timing of admission to the ED, we have divided the patients into two groups in order to see if there was any difference between the fasting hours (4:00-19:30) or nonfasting hours of the day (19:30-4:00). Data was obtained from 68 Muslim patients during the Ramadan month and 38 patients in the Non-Ramadan period. At the fasting hours during the Ramadan 43 patients $(63.2 \%)$ were admitted to the ED. A slightly higher percentage, but not statistically significant was seen in the NonRamadan period ( $=28,73.2 \%, \mathrm{p}=0.359)$.

\section{Discussion}

Renal Colic (RC) is one of the most frequent urologic reasons for Emergency Department (ED) referral, leading to a major burden on the health care system [1]. The most significant risk factors for urinary stone development include high salt and low fluid intake. The major finding of the current study is that Ramadan fasting is 
associated with nearly two-fold increase in the incidence of renal colic ED admissions among Muslims. This was not observed in nonMuslim patients who did not change their drinking and eating habits during the investigated periods. We also observed that once renal colic occurred regardless of fluid intake status, the size, location and severity of the event were similar among the studied groups and periods.This increased RC admission during the Ramadan fasting can be explained by several key factors:

The association of renal colic incidence and hydration is well established and was supported by pak et al who concluded in their study that fluid intake above $2.5 \mathrm{~L} / \mathrm{d}$ will achieve proper urinary dilution, probably due to reduce crystallization of calcium salts in urine[10].

Another possible causative event in the increase of RC admission may be attributed to the temperature during the Ramadan month in the geographic location of the study population. During this time period temperature is extremely hot and may reach up to $40^{\circ}$ Celsius(C) $\left(104^{\circ} \mathrm{F}\right)$ which is slightly less during the non-Ramadan period. This was also reported by others. For example, Sagy et al' have demonstrated a linear relationship between the rise in mean daily temperature and the ED visits due to renal colic: every increase in $1^{\circ} \mathrm{C}$ in the mean preceding week is associated with an increase of $2-4 \%$ in ED visits [11-14]. Our study protocol methodically overcame seasonal temperature changes bias by comparing the fasting population with a control group two weeks before and after Ramadan, logically with almost the same mean temperature. In our study we did not find any significant differences among ED visits during the first or last two weeks of the Ramadan month. However, other studies reported that the increase in RC events is most prominent during the first two weeks $[11,15]$.

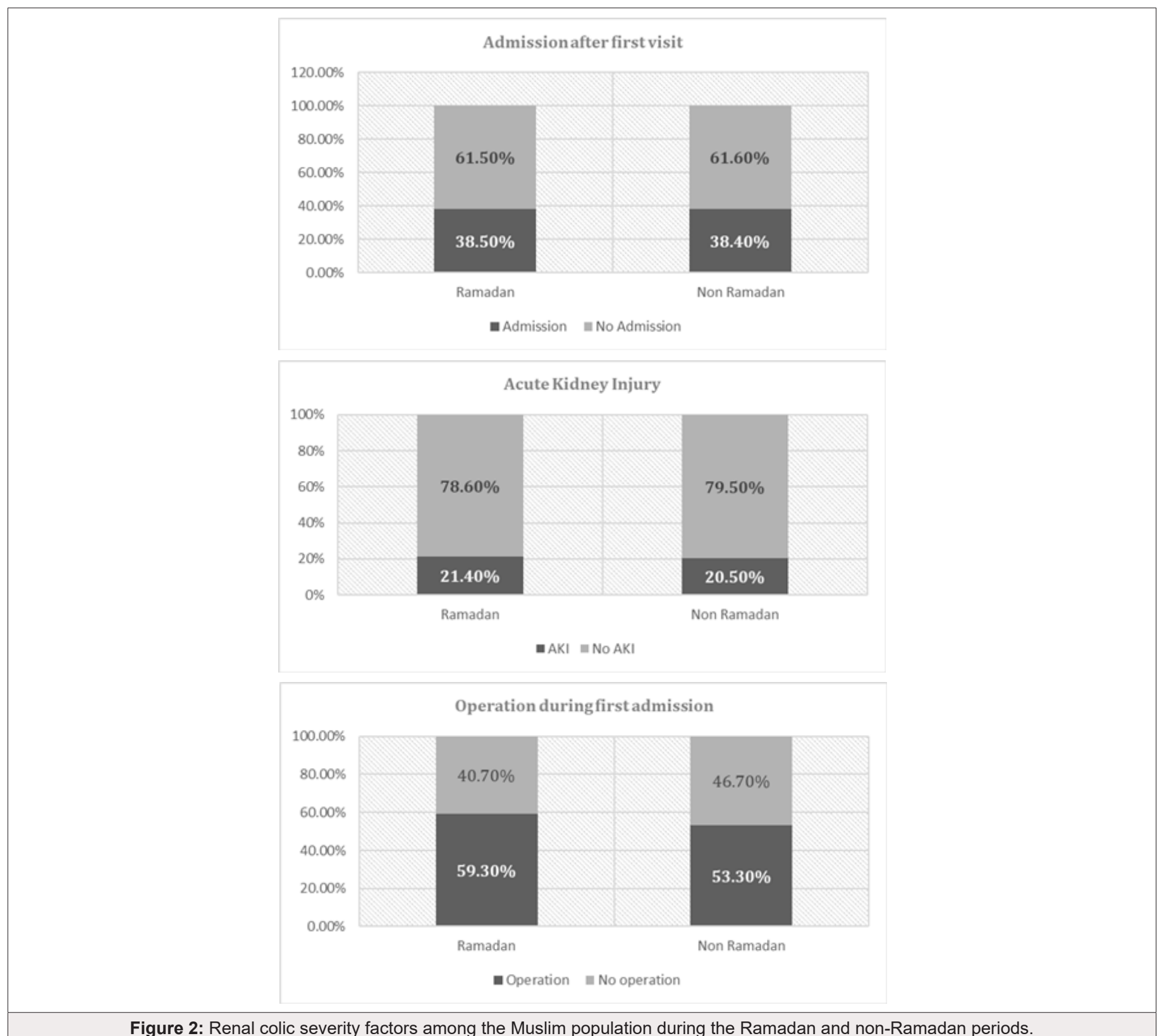

Figure 2: Renal colic severity factors among the Muslim population during the Ramadan and non-Ramadan periods. 
A possible explanation to this time point of event during the Ramadan month was provided by Kalaitzidis et al. they assume this is an adaptive response to the fasting stress that results in increase of some regulatory hormones in order to maintain homeostasis: ADH which alters urine output and ACTH that enhances hypercalciuria [16]. One point to consider is that during the Ramadan month, Muslims are exposed to dietary changes as a result of high meat consumption during the post-fasting meals. These changes may also contribute to stone formation by altering the biochemical composition of the urine. Zghal et al. [17] studied 90 patients who were divided into three groups: healthy fasting patients (G1), healthy non-fasting patients (G2), and non-fasting patients with calcium lithiasis (G3). They found that supersaturation of urine with oxalate, uric acid and brushite were increased in healthy fasting individuals, similar to non-fasting stone formers [17].

By contrast, Miladipour et al, [18] compared 24-hour urine collections of stone formers and non-stone formers before and during the Ramadan fasting. They reported no significant increase in calcium oxalate supersaturation during the Ramadan fasting period [18]. Our secondary outcome was to evaluate the severity of the renal colic events. Although we have found that during the Ramadan fasting there are more RC ED admissions, we could not find any statistically significant differences in the severity of these events. In other words, once a stone event occurred there is no difference whether the individual was fasting or not (Figure 2). our study has two main strengths. First, all renal colic events included in the study were diagnosed only by Non-Contrast CT scan which known as the gold standard. Most other published studies based the diagnosis of renal colic on clinical symptoms [19], Renal Ultrasound [18] and low percentage CT scan usage (30.7\%) as a diagnostic tool [11]

Second, the nature of research conducted in Israel known for its diverse population has allowed the appointment of a nonMuslim control population, and increases the reliability of our findings. Which except for one study [11], has not been possible in previous studies [18-22]. Our study carries several limitations. This was a single centered retrospective cohort. There was no exact data to confirm whether Muslim patients were actually fasting during the Ramadan month. To make a calculated estimation we relied our results on epidemiological studies for example, a recent Pew Research Center survey of more than 38,000 Muslims around the world showed a median of $93 \%$ of Muslims fast during the entire fasting period [23]. In Israel it is estimated that median is more similar to western countries where approximately $80 \%$ of Muslims do fast during the Ramadan month [24]. Finally, very few patients had metabolic evaluations of nephrolithiasis. That data would have been able to give us more information about the type of stones formed during the Ramadan month and would aid in better understanding the underlying pathophysiology.

\section{Conclusion}

In the current study we were able to demonstrate that during the month of the Ramadan, the likelihood of Muslim patients to admit to the ED with an acute RC event is nearly two-fold higher than in the non-Ramadan period. Dehydration seems to be the main risk factor for the occurrence of acute RC event during this fasting period. Once a renal colic event occurred there was no difference in severity whether there was prior fasting or not.

\section{Reference}

1. Justin B Z, Brian R Matlaga (2017) Epidemiology and economics of nephrolithiasis. Investig Clin Urol 58(5): 299-306.

2. Rule AD, Lieske JC, Li X, Melton LJ, Krambeck, et al (2014) The ROKS nomogram for predicting a second symptomatic stone episode. J Am Soc Nephrol 25(12): 2878-2886.

3. Bushinsky DA (2016) Nephrolithiasis. In: Goldman L \& Schafer AI (Eds.), Goldman-Cecil Medicine. (25 ${ }^{\text {th }}$ edn), Philadelphia, Elsevier Saunders chap PA, USA, pp.126.

4. Margaret SP, David SG, Dean GA, Gary Curhan, Cynthia JD, et.al (2014) Medical Management of Kidney Stones, American Urological Association guidelines. J Urol 192(2): 316-324.

5. Morgan MSC, Pearle MS (2016) Medical management of renal stones. BMJ 352: 1-12.

6. Dean A, Krambeck A, Nicole LM, Manoj M, Hassan MM (2016) Surgical management of stones: American Urological Assocaition/Endourological society guisdelines, PART I. J Urol 196(4): 1153-1156.

7. Biradar AN, Patil SB, Yadawe MS, Kundargi VS (2014) Influence of water quality on urolithiasis. World J Pharm Res 3: 483-487.

8. Azizi F (2010) Islamic fasting and health. Ann Nutr Metab 56(4): 273282.

9. Berbari AE, Daouk NA, Mallat SG, Jurjus AR, (2012) Ramadan fasting in health and disease. Springer Verlag pp.331-346.

10. Pak CY, Sakhaee K, Crowther C, Brinkley L (1980) Evidence justifying a high fluid intake in treatment of nephrolithiasis. Ann Intern Med 93(1): 36-39.

11. Sagy I, V Zeldetz, D Halperin, M Abu Tailakh, V Novack (2017) The effect of Ramadan fast on the incidence of renal colic emergency department visits. QJM: An International J Medic 110(9): 571-576.

12. Cervellin G, Comelli I, Comelli D, Cortellini P, Lippi G, et.al (2011) Regional short-term climate variations influence on the number of visits for renal colic in a large urban Emergency Department: results of a 7-year survey. Intern Emerg Med 6(2): 141-147.

13. Tasian GE, Pulido JE, Gasparrini A, Saigal CS, Horton BP, et.al (2014) Daily mean temperature and clinical kidney stone presentation in five U.S. metropolitan areas: A Time-Series Analysis. Environ Health Perspect 122(10): 1081-1087.

14. Boscolo BR, Dal MF, Abate A, Arandjelovic G, Tosato F, et.al (2008) Do weather conditions influence the onset of renal colic? A novel approach to analysis. Urol Int 80(1): 19-25.

15. Abdolreza N, Omalbanin A, Mahdieh TS, Mohammad Ali MR, Reza MS, et.al (2011) Comparison of the number of patients admitted with renal colic during various stages of peri-Ramadan month. Saudi J Kidney Dis Transpl 22(6): 1199-1202.

16. Kalaitzidis RG, Damigos D, Siamopoulos KC (2014) Environmental and stressful factors affecting the occurrence of kidney stones and the kidney colic. Int Urol Nephrol 46(9): 1779-1784. 
17. Zghal A, Fellah H, Zerelli L, Daudon M, Belkehia C, et.al (2005) Variation of biochemical parameters of the first morning urine during month of Ramadan. Tunis Med 83(10): 591-594.

18. Miladipour AH, Shakhssalim N, Parvin M, Azadvari M (2012) Effect of Ramadan fasting on urinary risk factors for calculus formation. Iran J Kidney Dis 6(1): 33-38.

19. Cevik Y, Corbacioglu SK, Cikrikci G, Oncul V, Emektar E (2016) The effects of Ramadan fasting on the number of renal colic visits to the emergency department. Pak J Med Sci 32(1): 18-21.

20. Assaad RG, Bachir R, Sayed MJ (2018) Impact of Ramadan on emergency department visits and on medical emergencies. Eur J Emerg Med 25(6) 440-444.
21. Abdullah AM, Sultan SA, Ibrahim HA, Abdullah AM, Muath IJ, et.al (2018) Does fasting in Ramadan increase the risk of developing urinary stones? Saudi Med J 39(5): 481-486.

22. Abdolreza N, Omalbanin A, Mahdieh TS, Mohammad Ali MR, Reza MS, et.al (2011) Comparison of the number of patients admitted with renal colic during various stages of peri-Ramadan month. Saudi J Kidney Dis Transpl 22(6): 1199-1202.

23. Ghandi F (2013) Findings from Pew's Research Center, Most Muslims say they fast during Ramadan.

24. Besheer M, Smith G, Cooperman A, Schiller A (2017) Pew Research Center U.S. Muslims Concerned About Their Place in Society, but Continue to Believe in the American Dream. 